\section{From passive subjects to equal partners}

\author{
Qualitative review of user involvement in research
}

PREMILA TRIVEDI and TIL WYKES

\begin{abstract}
Background The Department of Health and UK funding bodies have suggested that clinical academics work closely with mental health service users in research projects. Although there are helpful guidelines on the issues that have to be dealt with, there have been few examples of how this partnership research might be undertaken.
\end{abstract}

Aims To illustrate the challenges in joint research projects.

\section{Method We subjected the process of user involvement to ten questions which arose in the development of a joint research project. The answers are an amalgamation of the user and clinical researcher considerations and are affected by hindsight.}

Results The involvement of the userresearcher changed the focus of the study and its design and content. More attention was paid to the intervention itself and the way in which it was delivered. This process increased the amount of time taken to carry out and write up the project as well as incurring financial costs for user consultation payments and dissemination.

\section{Conclusions This experience has} clarified the contribution that users can make, for example by raising new research questions, by ensuring interventions are kept 'user friendly', and the selection of outcome measures.

\section{Declaration of interest None.}

In recent years the Department of Health, the National Health Service (NHS) Executive, research charities and funding bodies have emphasised the importance of user involvement in clinical research (Department of Health, 1998, 1999; Consumers in NHS Research, 1999; Hanley, 1999; Hanley et al, 2001; Royle \& Oliver, 2001) because users have 'the experience and skills to complement those of current researchers...they know what it feels like to undergo treatments and their various side effects...they will have a good idea about what research questions should be asked ... and how questions might be asked differently' (Goodare \& Lockward, 1999), and 'if the needs and views of users are reflected in research it is more likely to produce results that can be used to improve clinical practice' (Department of Health, 2000). Many clinical researchers therefore want to involve users in their research but are often unclear exactly how to go about this. Although useful briefing notes have been published (Consumers in NHS Research Support Unit, 1999, 2000), little detailed information is available about how the process works in practice or the philosophical, conceptual and practical challenges that may arise for clinical researchers when they seek to involve users in research, especially in the field of mental health where the massive imbalance of power that exists in services between professionals and users may make working together in research particularly challenging (Beresford \& Wallcroft, 1997; Lindow, 2001).

This review describes our experience of working together for the first time with user-researchers on a study investigating the effects of group medication education sessions on in-patients in our local psychiatric intensive care unit (PICU) (Kavanagh et al, 2002). We use this experience to describe each step in the partnership research process and the challenges we faced along the way. We certainly do not claim to have all the answers, but hope that our account will help others become more aware of the complexities of user involvement in mental health research.

Many terms are currently used to describe people who use mental health services: 'patient', 'consumer', 'client', 'user', 'survivor'. The term selected generally reflects a particular context or political perspective. In this review our focus on involvement led us to prefer the term 'user', although where users were in hospital we have (for the sake of clarity) referred to them as 'patients'.

\section{TEN QUESTIONS TO CONSIDER WHEN PLANNING JOINT RESEARCH}

\section{What is the value of user involvement?}

The first question to be resolved should be considered well before any contact with users and involves the clinical research team spending time to consider precisely why they want user involvement: is it merely to satisfy the requirements of funding and regulation bodies (Hanley, 1999, 2001), or is it because there is a considered and genuine belief in the value of user involvement (Goodare \& Lockward, 1999)? In our case, members of the clinical research team at the Centre for Recovery in Severe Psychosis (CRiSP) were clear that introducing a user perspective could positively influence the content of their research and make it more relevant to clinical practice.

\section{How will users be involved in the research process?}

User involvement in research may occur at many different levels (Lindow, 2001), ranging from lip-service involvement (where researchers consult with users but maintain ultimate control of the project) to partnership involvement (where researchers actively work with users as collaborative partners, equitably sharing all final decision-making and control). Our clinical research team was philosophically inclined towards partnership involvement but probably did not fully appreciate (before they embarked on it) just how time-consuming and challenging it should be. 


\section{What projects might be suitable for user involvement?}

There is scope for user involvement in all clinical research, but certain projects may be more attractive than others - in particular those arising in response to users' requests and those that seek to increase user empowerment (Beresford \& Wallcroft, 1997; Church, 1997; Faulkner \& Layzell, 2000; Faulkner \& Nicholls, 2000; Rose, 2001). In our case the medication education project seemed particularly appropriate because it arose directly in response to requests from patients on the PICU at the Maudsley Hospital for more information about medication. This led to a decision to provide group medication education sessions, and the clinical research team saw this as an important opportunity to investigate (in line with previous studies: Brown et al, 1987; Macpherson, 1996; Tempier, 1996) the effects on patient knowledge, insight and compliance. Following further discussion the team came to the conclusion that since the study had been initiated by patients, it was important to maintain the patient focus by having active user involvement, and the decision was made to use the project to involve users actively for the first time in the team's research.

\section{What proposal will be prepared for presentation to users?}

Once the decision to involve users has been made, a clear outline of the proposed research should be prepared to present to users. It is probably not useful, however, at this stage to set out a precise proposal with little apparent scope for user intervention. The importance of this became clear to us only when the clinical research team presented their research protocol (with the research question, study design and outcome measures already firmly in place) to users, and received a very firm and negative response (see below).

\section{How will the initial approach be made to users?}

One of the most productive ways of approaching users is through relationships that have already been established locally (e.g. with user groups, user liaison workers or user development workers), but less direct approaches (e.g. through posters or advertising in magazines, newsletters and papers) may also be useful and might possibly recruit a wider range of users. In our study, the team knew there was an active user group (Communicate) in the local Trust and, following advice from the Trust's user liaison worker, submitted the research proposal in writing for the group's consideration.

\section{How will users' responses be considered?}

One of the most challenging aspects of user involvement for clinical researchers may be considering users' responses to their research proposals, especially if the responses are negative, spirited and passionate. Although it may be tempting to dismiss these responses as those of users with a personal agenda or an 'axe to grind', it is important to remember that users' responses come about largely through their experience of using services and - since it is this very experience that user involvement is trying to harness - their views, values and opinions need to be taken seriously if they are really to influence research. In our case, users responded by saying that they had considered the proposal carefully but were not prepared to be involved in a project that placed such importance on outcome measures of insight and compliance. They explained that although these outcomes might be extremely important for clinicians, they were anathema to many users who perceived them as echoing the paternalistic and disempowering authority of psychiatry, with 'having insight' too often meaning 'agreeing with professionals' and 'being compliant' meaning 'doing what you are told by professionals' (Perkins $\&$ Repper, 1999).

While somewhat taken aback by this strong and negative response, the leader of the clinical research team was sufficiently stimulated to ask for further discussion. This resulted in a series of lengthy meetings between the lead researcher and a member of Communicate charged with making the group's position clear. These meetings were often challenging and not always comfortable, but they served an important purpose in allowing a mutually respectful relationship to build up between clinical researcher and user, which eventually enabled them to agree to look again at the project and consider working on it together in partnership research.

\section{Will research partnerships with users be formalised?}

Within any clinical research team there is always a tacit and usually overt agreement on how individual members of the team will work together, how financial overheads will be shared and how research output will be attributed for assessment purposes. This is also important when users become involved with clinical researchers. An explicit agreement about how they will work together is necessary, addressing issues such as when and how users will be involved in the research, payment of users, acknowledgement of users' contributions, and issues of confidentiality. We used a research contract which Communicate had developed some years earlier (see Appendix). Although the contract had no legal standing, it was felt to be important in setting out clearly how the interests of users should be protected. This contract is now being amended to reflect the partnership and will cover more issues raised by the clinical researchers.

In addition to formalising the research partnership between the user and the clinical research team at a team and user group level with the research contract, the research partnership was also formalised at an institutional level by including the user (hereafter called the user-researcher) as a member of the clinical research team on the team's application to the institution's research ethics committee.

\section{How will the proposal be jointly assessed?}

The best way of evaluating the outline is to subject the proposal to a series of questions (examples given below) and then adjust the protocol, preferably before starting any practical work. In our study not all of these questions were apparent at the start of the project - some only emerged following user observation of how the research intervention (medication education sessions) was being delivered - and the answers to our questions did not come easily. The solutions to user concerns in the project were, in the end, far from perfect, but were the best pragmatic compromise that could be reached at the time.

\section{How did the research come about and does it address users' priorities?}

Our study came about directly as a result of patients requesting information about their 
medication, was obviously relevant to them, and by providing medication education sessions (in spite of some scepticism from ward staff) showed that patients' priorities were being taken seriously.

\section{What is the purpose of the study and does it contribute to user empowerment?}

The original purpose of the study was to provide medication education sessions and assess the effects on patient knowledge, insight and compliance. The user-researcher pointed out that while insight and compliance might be of major importance to clinicians, users would be interested in the effects of medication education on the empowerment of users, which was completely ignored in the original proposal. Empowerment here means imbuing strength, confidence, authority and power.

\section{What outcomes should be assessed, and are they what users consider to be important?}

It was agreed that the outcomes of medication education should be viewed more widely than had been initially suggested, with the focus shifted away from insight and compliance towards measures of patient empowerment. However, at the time there was no standard method for assessing these and, reluctantly for the users, insight and compliance had to remain major outcome measures. In writing the paper the emphasis was specifically shifted away from compliance and it is hoped that, in the future, more work with service users will enable us to develop appropriate methods for assessing patient empowerment (e.g. Rogers et al, 1997).

In addition to considering the patient outcome of medication education, we were also aware that the medication education sessions might have important effects on ward staff, some of whom expressed the fear that providing medication education would only make their work more difficult if patients (through becoming more knowledgeable and empowered) became less compliant and more questioning about their medication. These fears proved unfounded, and in fact ward staff found that, by clarifying information about medication and helping to dismiss myths about prescribing practices, the medication education sessions actually made their communication about medication with patients much easier. While this change in attitude was not formally measured it was very apparent, and made clear to us that in future studies it would be important to measure secondary effects of interventions on clinical staff as well as the direct effects on patients.

Is the intervention 'user friendly' and is enough importance attached to delivery of the intervention?

From the start the user-researcher (a former teacher) emphasised that the way the medication education intervention was delivered was important. In particular, she was concerned that if the intervention was seen to 'fail', patients would be blamed for not engaging with the sessions, rather than looking at whether the delivery of the sessions was appropriate. Factors that might influence the success or failure of the intervention included the physical environment where sessions were to be delivered, the skill of the teacher/facilitator/ empowerer in fulfilling the many different roles he or she would have to play during the sessions, and the ethos and attitudes of clinical staff towards patients who were taking part in the sessions. Clarification and acknowledgement of the importance of 'non-specific' factors in the implementation and effectiveness of a therapy or intervention reminded us to be very aware of such factors in all medical and psychological interventions, since they can often mean the difference between success and failure of the intervention.

\section{Are the methodology and design of the study appropriate?}

Although service user-researchers may not be experts in research methodology or design, they may still be able to make useful contributions to these aspects of a research project. For example, in our study the original proposal was to compare individual patients on the PICU with individual patients on an acute ward, controlling for factors such as length of illness. The userresearcher pointed out that since different clinical teams in the hospital were known to have very different attitudes to medication information, this could markedly affect how patients responded to the medication education sessions. This awareness led us to the specific use of the matching procedure used in our study and thus improved the scientific method of the investigation.
How will data be analysed and the results interpreted?

Although the type of data analysis may be fixed, the interpretations of data may vary considerably depending on who is doing the interpreting, since tables of data rarely come with their own prepackaged explanations and no interpretation is value-free. For example, clinical researchers might (to increase the likelihood of publication and future research funds) emphasise a positive, 'half-full' interpretation, while userresearchers might be more willing to stress a less positive, 'half-empty' version. Working with different interpretations of the same data may provide new and exciting lines of inquiry which had not been obvious at the beginning of the study.

\section{How will the project be written up?}

Where users have been involved in research, they should also be involved in documentation of the project, certainly in checking that papers submitted for publication reflect the users' impact on the study and properly acknowledge their contribution, for example through coauthorship. In our study there was some debate as to whether the user-researcher wished to be a co-author on a paper which, even after her involvement, still had a major focus on insight and compliance (Kavanagh et al, 2002). Eventually it was agreed that since much more had come out of the study than had been originally intended, two papers would be written, one on the actual medication education study, and the current paper on the process of user involvement in that study. Under these circumstances the user-researcher agreed to be a co-author on both papers.

\section{How will dissemination occur?}

The dissemination of clinical research findings generally occurs only in peer-reviewed journals and during academic conference presentations. These usually have an impact only on a relatively small number of clinicians who are research-oriented, and the Department of Health and funding bodies have stressed that a much wider dissemination process is necessary. In particular, dissemination to users is essential since, in the new consumer orientation of the UK NHS, it is not only evidence-based, randomised, controlled trials that determine what interventions are introduced into clinical practice, but also consumer demand 
(Department of Health, 1999). Furthermore, research 'subjects' (whether they be users or staff) are often the last people to know the results of the project in which they have participated, and are frequently left feeling used and unclear about how the research they have participated in will influence clinical practice (Patel, 1999). One option which has been adopted by CRiSP in the South London and Maudsley NHS Trust is to produce a newsletter for research participants informing them of the latest results of its projects. Alternatively, web pages can be produced or talks organised with service user networks and local community groups. The involvement of users in these types of dissemination is essential so that information is presented in an easily accessible and relevant form and any queries are addressed in an appropriate way.

\section{CONCLUSIONS}

We have set out the process of involving users in clinical research and have illustrated from our own experience how this may be challenging but also profitable, not only for clinical researchers but for the health services in general. The broader perspective introduced into the content of the study by the user has very much shaped our thinking. We have designed other clinical trials to incorporate such measures as a sense of empowerment, self-esteem and alliance with the clinical team as primary outcomes. Clearly, more research on outcome measures that service users value and that have clear psychometric properties is essential to further collaborative efforts.

We would not want clinical researchers to be unaware of the costs as well as the benefits of a collaboration with service user-researchers. If user-researchers are to be closely involved then a time commitment needs to be given to this process in the research proposal and this must be costed into the project's finances. Service users also need to be paid for their time (as clinical academic staff are). Not only do these costs have to be included in the proposal but they are also difficult to implement, as there are limits to the payment of service users who claim benefits. The commitment to collaboration will be demanding of the research team too as its members come to terms with the competing objectives (Oliver, 1992). These increased demands need to be recognised by research funders if collaborations are to be encouraged in the future.

Many mental health users may not wish to be involved in partnership research (Faulkner \& Nicholls, 2000), although a recent local conference in south London indicated that service users can set priorities for research and would like more involvement (Thornicroft et al, 2002). However, the main problem that emerged was their lack of confidence in the research process. We have therefore set up a collaborative organisation between service users and academic staff, the Service User Research Enterprise (SURE), with the aim of helping to increase confidence through training programmes involving both service users and clinical researchers, which we hope will begin to break down the barriers on either side. The research community has much to gain from these collaborations and we hope to play some part in fostering them.

\section{ACKNOWLEDGEMENTS}

We thank Communicate, the users' group at the Maudsley Hospital, for allowing us to use and publish their research contract. We particularly acknowledge the work of Lisa Barcan, Su Glazier and Dawn Batcup, who (together with P.T.) played a crucial part in developing this contract.

\section{APPENDIX}

\section{Text of partnership research contract designed by the \\ Communicate user group to protect users' interests}

Partnership research contract between Communicate and

Title of research study

Principal and other clinical researchers

User-researchers

As principal clinical researcher on the above research study involving the participation of members of Communicate, I agree that the study will:

I. Demonstrate to Communicate's satisfaction that the research project contributes to user empowerment and equal opportunities.

2. Involve users in the research process from the beginning to the end as equal partners who share in control of and decision-making about the research.

3. Show that confidentiality, ethics and informed consent will be built into the project at the outset, and that access to user participants will be negotiated in appropriate and empowering ways and they will be informed of the results of the study.

4. Include provision for support and supervision of user-researchers throughout the project.
5. Pay user-researchers the going rate for their contribution, and ensure payment is made in ways and time-frame negotiated with the user.

6. Acknowledge the contribution of userresearchers in all documentation and at al presentations, and provide user-researchers with copies of such.

\section{Have the approval of Communicate.}

As principal investigator I will take responsibility for ensuring that all others involved in this project are aware of the conditions of this contract and adhere to its principles. If at any time it appears that any of the above criteria are not being met, service users will review their position and reserve the right to opt out of the research project. [To be signed by the principal investigator for the clinical research team and countersigned by the service userresearcher for Communicate.]

Note: This contract is essentially between the clinical research team and Communicate so that if problems arise during the partnership research for individuals they have constituencies to go back to for support and guidance.

Section 4 may also include a statement about what will happen if the user becomes (or is perceived as becoming) 'ill'during the research, so for example users will only be referred to their clinical team if that has been previously agreed.

\section{REFERENCES}

Beresford, P. \& Wallcroft, J. (1997) Psychiatric system survivors and emancipatory research: issues, overlaps and differences. In Doing Disability Research (eds C. Barnes \& G. Mercer), pp. 67-87. Leeds: Disability Press,

Brown, C. S., Pharm, D., Wright, R. G., et al (1987) Association between type of medication education and patients' knowledge, side effects and compliance. Hospital and Community Psychiatry, 38, 55-60.

Church, K. (1997) Madness in her method: creating a 'survivor frame' for mental health research. Journal of Psychiatric and Mental Health Nursing, 4, 307-308.

Consumers in NHS Research (1999) R\&D in the NHS How Can You Make a Difference? Leeds: NHS Executive.

Consumers in NHS Research Support Unit (1999) Involving Consumers in Research and Development in the NHS: Briefing Notes for Researchers. London: Department of Health.

- (2000) Consumers involvement in South London and Maudsley NHS Trust. Consumers in NHS Research Support Unit News, summer 2000, 3.

Department of Health (1998) Research - What's In It for Consumers? Report of the Standing Advisory Committee on Consumer Involvement in the NHS Research \& Development Programme. London: Department of Health.

_ (1999) Patient and Public Involvement in the New NHS. London: Department of Health.

- (2000) Working Partnerships. Consumers in Research Third Annual Report. London: Department of Health.

Faulkner, A. \& Layzell, S. (2000) Strategies for Living: A Report of User-Led Research into People's Strategies for Living with Mental Distress. London: Mental Health Foundation.

— \& Nicholls, V. (2000) The DIY Guide to Survivor Research. London: Mental Health Foundation.

Goodare, H. \& Lockward, S. (1999) Involving patients in clinical research. BMJ, 319, 724-725. 
Hanley, B. (1999) Involvement Works. Second report of the Standing Advisory Committee on Consumer Involvement in the NHS Research \& Development Programme. London: Department of Health

\section{_ , Trusdale, A., King, A., et al (200I) Involving consumers in designing, conducting and interpreting randomized clinical trials. BMJ, 322, 519-522.}

\section{Kavanagh, K., Duncan-McDonnell, D., Greenwood,} K., et al (2002) Educating inpatients about their medications: is it worth it? Journal of Mental Health, in press.

Lindow, V. (200I) Survivor research. In This is Madness Too (eds C. Newnes, G. Holmes \& C. Dunn), p. 14-25. London: PCCS Books.

Macpherson, R., Jerrom, B. \& Hughes, A. (1996) A controlled study of education about drug treatment in schizophrenia. British Journal of Psychiatry, 168, 709-717.

Oliver, M. (1992) Changing the social relations of research production. Disability, Handicap and Society, $\mathbf{7}$. 83-87.

Patel, N. (1999) Getting the Evidence - Guidelines for Ethical Mental Health Research. London: Mind.

Perkins, R. E. \& Repper, E. M. (1999) Compliance or informed choice. Journal of Mental Health, 8, I17-129.

Rogers, E. S., Chamberlin, J., Ellison, M. L., et a (1997) A consumer-constructed scale to measure empowerment among users of mental health services. Psychiatric Services, 48, 1042-1047.

Rose, D. (200I) Users' Voices. London: Sainsbury Centre for Mental Health.

Royle, J. \& Oliver, S. (200I) Consumers are helping to prioritize research. BMI, 253, 48-49.

\section{CLINICAL IMPLICATIONS}

Service user involvement can benefit research.

- This paper sets out a guide to research partnership including the difficulties and their solutions.

\section{LIMITATIONS}

- The model has only been tested in controlled treatment evaluations.

- The range of research for which this model is applicable has not been tested.

It is not clear whether some research methods require research skill training prior to successful partnership.

PREMILA TRIVEDI, PGCE, Share in Maudsley Black Action; TILWYKES, PhD, Service User Research Enterprise, Institute of Psychiatry, London, UK

Correspondence: Professor Til Wykes, Department of Psychology, Institute of Psychiatry, De Crespigny Park, Denmark Hill, London SE5 8AF, UK

(First received 2I March 2002, final revision 28 June 2002, accepted 2 July 2002)

Tempier, R. (1996) Long-term psychiatric patients' knowledge about their medication. Psychiatric Services, 47, 1385-1387.
Thornicroft, G., Rose, D., Huxley, P., et al (2002) What are the research priorities of service users? Journal of Mental Health, II, I-5. 